\title{
NOVAS ESPÉCIES DE TRICHOMYIA (DIPTERA, PSYCHODIDAE) DA MATA ATLÂNTICA DA BAHIA, NORDESTE DO BRASIL
}

Freddy Bravo ${ }^{1}$

\begin{abstract}
NEW SPECIES OF TRICHOMYIA FROM ATLANTIC RAIN FOREST OF BAHIA, NORTHEASTERN BRAZIL. Six new species of Trichomyia from Atlantic rain forest of Bahia, northeastern Brazil, are described: T. itabunensis, T. onorei, T. queirozi, T. silvatica, T. sulbaianensis and T. teimosensis. The first two have palpi with four segments, similar to the other Neotropical species. The other four species have palpi with three segments, similar to other species with wide world distribution.
\end{abstract}

KEYWORDS. Psychodidae, Trichomyia, taxonomy, Atlantic forest, Neotropical.

\section{INTRODUÇÃO}

Do gênero Trichomyia Haliday, 1839, são conhecidas sessenta e nove espécies neotropicais (RAPP, 1945; DuCKHOUSE, 1972, 1973; WAGNER, 1993, 1999; QuATE, 1996, 1999; Wagner \& Masteller, 1996; Bravo, 1999, 2000, 2001a, b, c; AleXANDER et al., 2001). Do Brasil, foram descritas vinte e quatro espécies (BARRETTO, 1954a, b; SATCHELL, 1956; BRAVO, 1999, 2000, 2001a, b, c; AleXANDER et al., 2001) e T. cirrta, descrita do México porCoQuilLET (1902), foi registrada no Brasil (SATCHELL, 1956).

O número de segmentos do palpo maxilar tem sido usado para discutir afinidades entre as espécies de Trichomyia (BRAVO, 2000). Onze das espécies brasileiras apresentam palpo maxilar com quatro segmentos, sendo que os dois primeiros estão parcialmente fundidos, característica vista somente nas espécies neotropicais (BRAVO, 2000). As outras quatorze apresentam palpo maxilar com três segmentos. Descrevem-se seis espécies novas de Trichomyia das matas úmidas da Bahia, duas das quais possuem quatro segmentos e as outras quatro, três segmentos no palpo maxilar.

\section{MATERIAL E MÉTODOS}

Os espécimens estudados estavam conservados em álcool $70 \%$. Foram tratados com solução aquosa de hidróxido de potássio $(\mathrm{KOH})$, montados em lâmina permanente e depositados na Coleção Entomológica da Universidade Estadual de Feira de Santana (CUFS), Feira de Santana, Bahia. Segue-se o sistema para as nervuras alares proposto por Colless \& MCAlpine (1991) e as demais terminologias

1. Departamento de Ciências Biológicas, Universidade Estadual de Feira de Santana, Av. Universitária s/n, 44031-460, Feira de Santana, BA, Brasil. (fbravo@uefs.br) 
seguem McAlpine (1981).

Os espécimens procedem de matas úmidas de três localidades da Bahia (matas inseridas no Bioma Mata Atlântica): Itabuna $\left(14^{\circ} 45^{\prime} \mathrm{S}-39^{\circ} 15^{\prime} \mathrm{W}\right)$ e Jussari (Serra do Teimoso, $15^{\circ} 9^{\prime} \mathrm{S}-39^{\circ} 31^{\prime} \mathrm{W}$ ) no sul da Bahia e Pedra Branca (Serra da Jibóia, $12^{\circ} 51^{\prime} \mathrm{S}-39^{\circ} 30^{\prime} \mathrm{W}$ ) no centro-leste da Bahia.

\section{Trichomyia itabunensis sp. nov.}

(Figs. 1-6)

Material-tipo. BRASIL, Bahia: Itabuna (Reserva Ecológica CEPEC), holótipo ơ, 10.X.1985, P. S. Terra col. (CUFS).

Etimologia. O adjetivo específico é alusivo à cidade onde o espécime foi coletado.

Diagnose. Palpo maxilar com três segmentos. Terminália masculina: gonocoxitos com uma projeção lateral, digitiforme, em formato de C. Cercos digitiformes com três

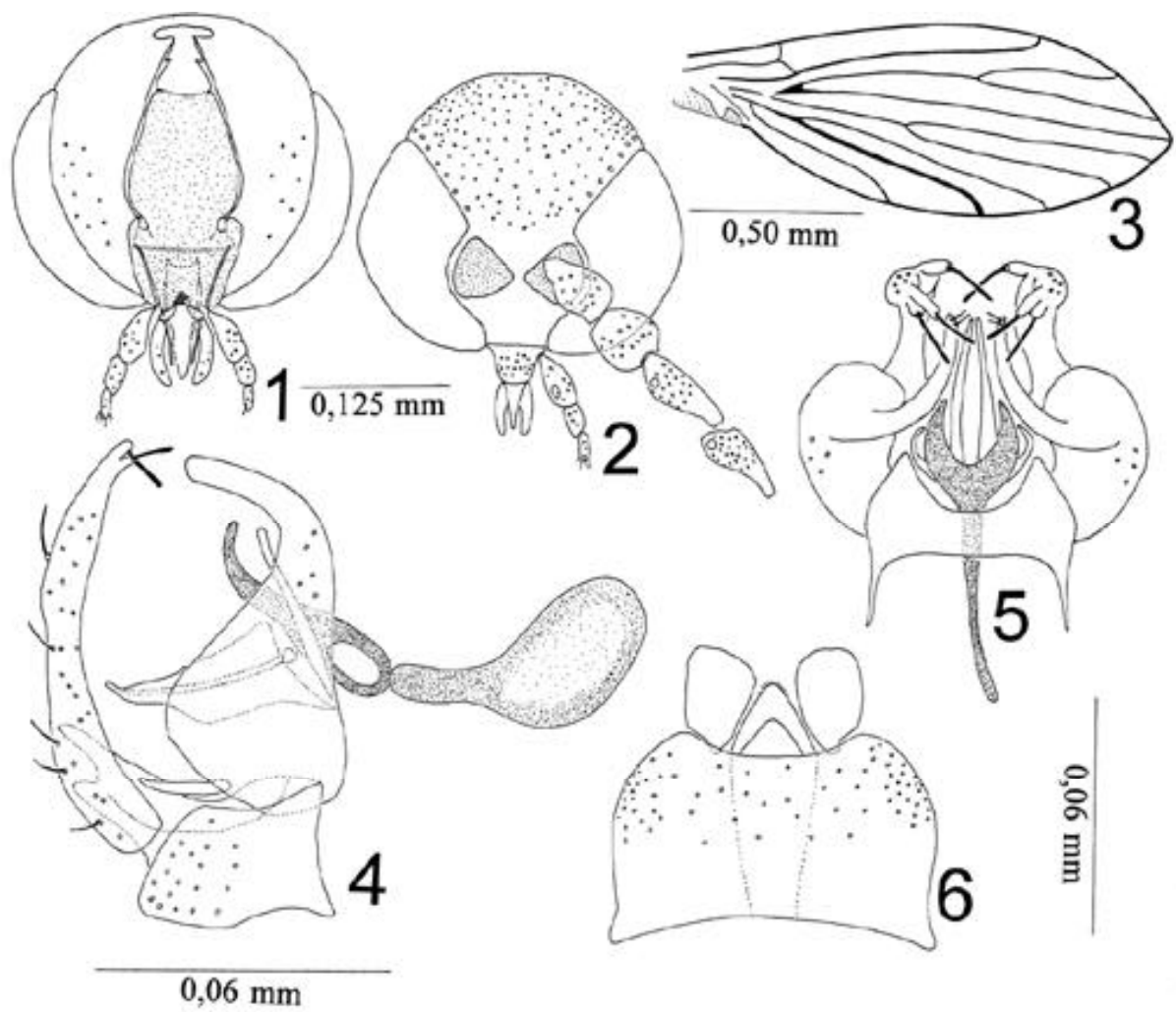

Figs. 1-6. Trichomyia itabunensis sp. nov. Cabeça: 1, posterior; 2, anterior; 3, asa direita; terminália masculina: 4, lateral; 5, dorsal; 6, ventral. 
cerdas longas e grossas no ápice. Ápice do apódema ejaculador semelhante a um bulbo. Descrição. Macho, comprimento do corpo, 1,22 mm. Cabeça subcircular (figs. 1, 2). Palpo maxilar com três segmentos; comprimento relativo dos segmentos do palpo: 1,0:0,5:0,4 (figs. 1,2); fossa sensorial localizada no primeiro segmento (fig. 2). Antena incompleta no espécime estudado; escapo subcilíndrico e pedicelo subesférico, mais ou menos do mesmo tamanho (fig. 2); flagelômeros basais piriformes (fig. 2), ascóides perdidos no exemplar estudado. Comprimento da asa, $1,43 \mathrm{~mm}$; largura máxima, $0,57 \mathrm{~mm} ; \mathrm{r}-\mathrm{m}$ ausente; $\mathrm{M}_{4}$ esclerotinizada; m-cu ausente (fig. 3). Tergito 9, cercos e gonocoxitos com pilosidade (figs. 4, 6). Ápice do esternito 10 com micropilosidade na superfície dorsal (fig. 6). Tergito 9 sub-retangular (fig. 6). Tergito 10 pequeno e triangular (fig. 6). Cercos compridos, digitiformes, com três longas e grossas cerdas no ápice (fig. 4). Esternito 9 fundido aos gonocoxitos (fig. 5). Gonocoxitos com uma projeção lateral digitiforme, curva, lateralmente em formato de C (figs. 4, 5). Gonóstilos articulados ventralmente aos gonocoxitos, pequenos, digitiformes, pouco esclerotinizados (fig. 4). Esternito 10 comprido (fig. 6). Edeago simétrico (fig. 5); dois pares de parâmeros, um comprido, bem esclerotinizado e outro menor, pouco esclerotinizado (figs. 4, 5). Ponte gonocoxal não observada. Apódema ejaculador largo (figs. 4, 5), largo anteriormente, semelhante a um bulbo (fig. 4).

\section{Trichomyia onorei sp. nov.}

(Figs. 7-13)

Material-tipo. BRASIL, Bahia: Itabuna (Reserva Ecológica CEPEC), holótipo Oొ, 04.VI.1984, P. S. Terra col. (CUFS).

Etimologia. Denominada em homenagem ao Prof. Giovani Onore da Pontifícia Universidad Católica del Ecuador.

Diagnose. Palpo maxilar com quatro segmentos; fossa sensorial nos dois primeiros palpômeros. Asa com r-m ausente. Terminália masculina: cercos unidos por uma ponte esclerotinizada, estreita lateralmente e projetada posteriormente; apódema ejaculador longo e projetado para fora do gonocoxoesternito (esternito $9+$ gonocoxito). Ponte gonocoxal não evidente.

Descrição. Macho, comprimento do corpo, 1,91 mm. Cabeça subcircular. Palpo maxilar com quatro segmentos; comprimento relativo dos segmentos do palpo: 1,0:0,8:1,0:1,2 (fig. 8); fossas sensoriais localizadas no primeiro e segundo segmentos (fig. 8). Antena incompleta no espécime estudado; escapo subesférico e pedicelo subcilíndrico, mais ou menos do mesmo tamanho (fig. 7); flagelômeros piriformes, ascóides perdidos (fig. 7). Comprimento da asa, $1,88 \mathrm{~mm}$; largura máxima, $0,88 \mathrm{~mm}$; $r$-m ausente; $\mathrm{M}_{4}$ bem esclerotinizada; m-cu ausente (fig. 9). Tergito 9, cercos e gonocoxitos com pilosidade (figs. 10, 13). Ápice do esternito 10 com cerdas pequenas e grossas na superfície dorsal (fig. 13). Tergito 9 sub-retangular ventralmente (fig. 13). Cercos subquadrados, com cerdas grossas na margem apical (fig. 10); cercos unidos por uma ponte esclerotinizada, estreita lateralmente e projetada posteriormente (fig. 12). Esternito 9 fundido aos gonocoxitos, com cerdas grossas na margem apical (figs. 10,11); gonocoxitos sem projeções. Gonóstilos digitiformes, pouco esclerotinizados, fundidos basalmente, divergentes entre si (figs. 10, 11). Esternito 10 comprido, largo apicalmente (figs. 12, 13). Edeago simétrico (figs. 10,11) com um par de parâmeros (fig. 11); apódema ejaculador longo, projetado para fora do gonocoxoesternito (figs. 10, 11). Ponte gonocoxal não visível. 


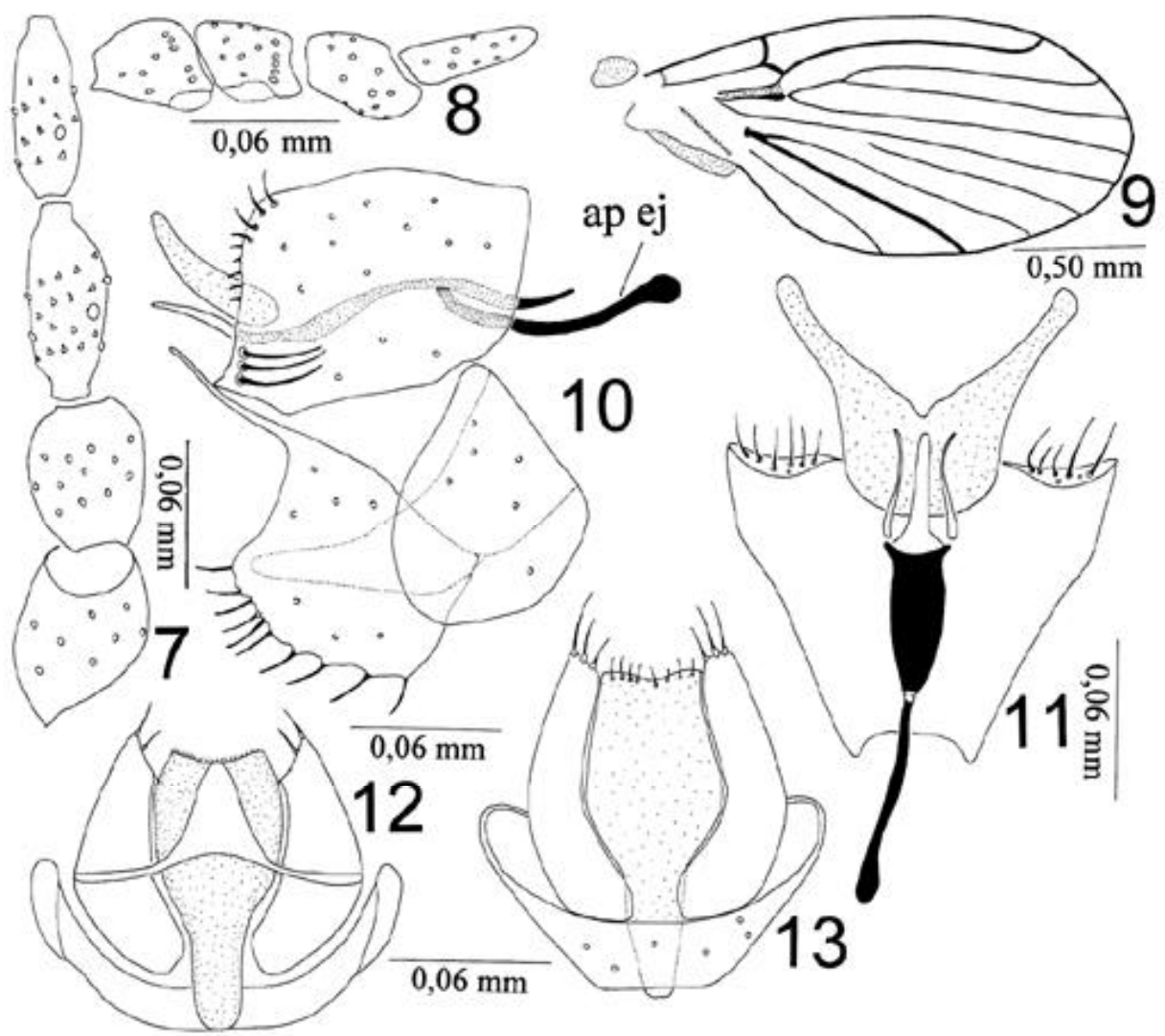

Figs. 7-13. Trichomyia onorei sp. nov.: 7, escapo, pedicelo e primeiros flagelômeros; 8, palpo maxilar; 9 , asa direita; 10 , terminália masculina, lateral; 11, gonocoxoesternito, gonóstilos, edeago e apódema ejaculador, ventral; tergito 9 , esternito 10 e cercos: 12, ventral; 13, dorsal (ap ej, apódema ejaculador).

\section{Trichomyia queirozi sp. nov.}

(Figs. 14-21)

Material-tipo. BRASIL, Bahia: Serra da Jibóia, holótipo O', 01.IV.2001, I. Castro col. (CUFS).

Etimologia. Denominada em homenagem ao Dr. Luciano P. de Queiroz, da Universidade Estadual de Feira de Santana, pelo apoio brindado ao estudo dos Psychodidae.

Diagnose. Palpo maxilar com quatro segmentos; fossa sensorial nos dois primeiros palpômeros. Asa com r-m. Terminália masculina: cercos sem ponte dorsal que os una; apódema ejaculador não projetado para fora do gonocoxoesternito.

Descrição. Macho, comprimento do corpo, 1,79 mm. Cabeça subcircular. Palpo maxilar com quatro segmentos; comprimento relativo dos segmentos do palpo: 1,0:1,0:1,3:1,7 (fig. 


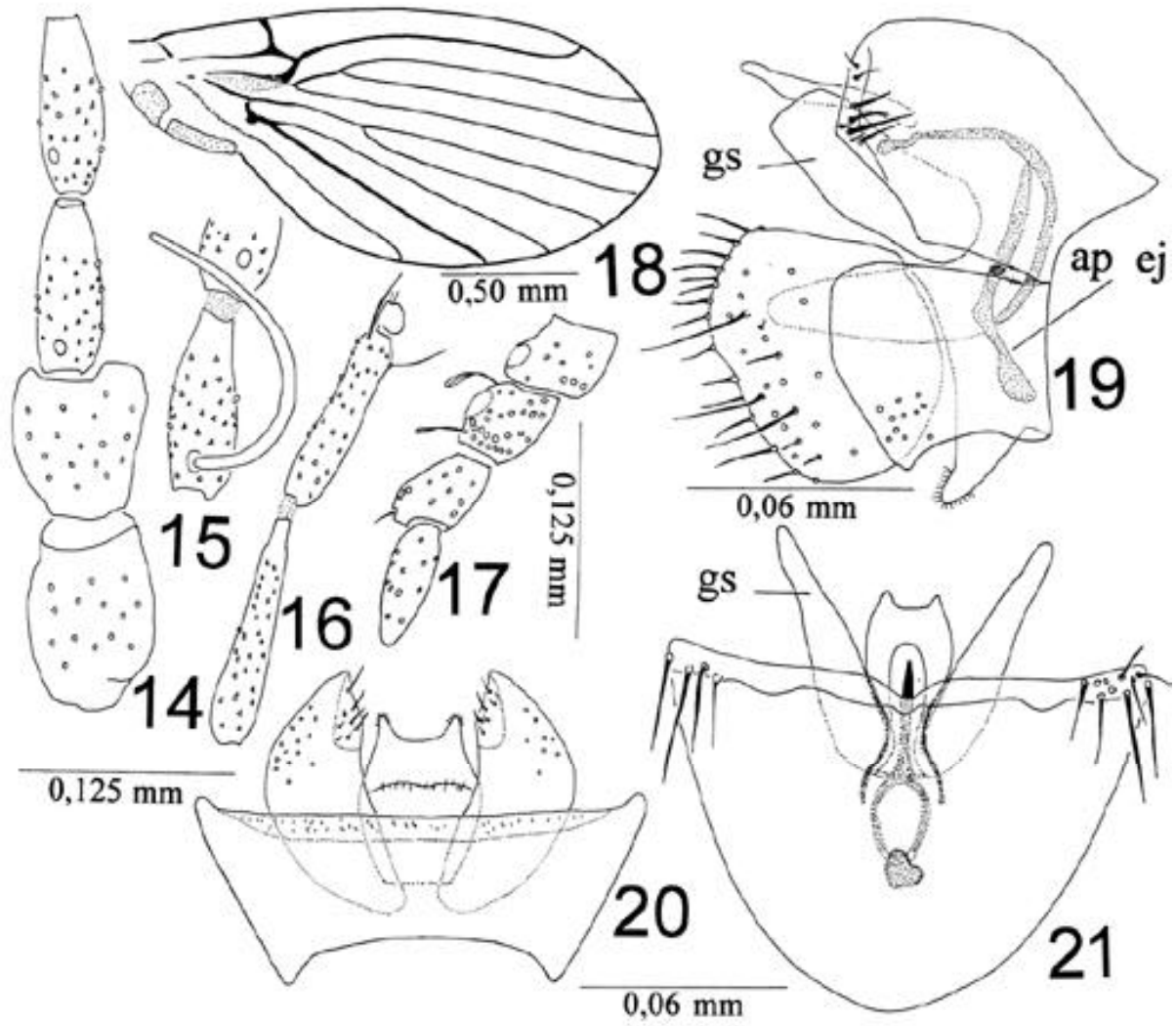

Figs. 14-21. Trichomyia queirozi sp. nov.: 14, escapo, pedicelo e primeiros flagelômeros; 15, flagelômero 3 com ascóide; 16, flagelômeros 12 e 13, com apículo terminal; 17, palpo maxilar; 18, asa direita; terminália masculina: 19, lateral; 20, ventral; 21, dorsal (ap ej, apódema ejaculador; gs, gonóstilo).

17); fossas sensoriais no primeiro e segundo segmentos (fig. 17). Antena com 13 flagelômeros, o último com apículo separado por sutura (fig. 16); escapo e pedicelo subcilíndricos, mais ou menos do mesmo tamanho (fig. 14); flagelômeros basais piriformes (fig. 14); ascóides com formato de C (fig. 15). Comprimento da asa, 1,90 mm; largura máxima, $0,90 \mathrm{~mm}$; $r$-m ausente; $M_{4}$ esclerotinizada; $\mathrm{m}$-cu presente (fig. 18). Tergito 9 , cercos e gonocoxitos com pilosidade (figs. 19,20). Ápice do esternito 10 com micropilosidade lateral (fig. 20). Tergito 9 sub-retangular (fig. 20). Tergito 10 pequeno e estreito, com micropilosidade apical (fig. 20). Cercos subesféricos, grandes, sem cerdas especiais no ápice e sem ponte dorsal que os una (figs. 19,20). Esternito 9 fundido aos gonocoxitos, subtriangular (fig. 21), com cerdas grossas na margem apical (figs. 19, 21). Gonocoxitos sem projeções. Gonóstilos digitiformes, pouco esclerotinizados (figs. 19, 21), divergentes entre si, não unidos basalmente (fig. 21). Esternito 10 longo, com depressão medial (fig. 
20). Edeago simétrico (fig. 21); parâmeros fundidos formando cápsula ao redor do edeago (fig. 21); apódema ejaculador longo, não projetado para fora do gonocoxoesternito (figs. 19, 21).

\section{Trichomyia silvatica sp. nov.}

(Figs. 22-27)

Material-tipo. BRASIL, Bahia: Itabuna (Reserva Ecológica CEPEC), holótipo ơ", 10.X.1985, P. S. Terra col. (CUFS).

Etimologia. Do latim silvaticus, que vive nas florestas.

Diagnose. Palpo maxilar com três segmentos. Terminália masculina: gonocoxitos com dois pares de projeções laterais; a dorsal, estreita, com ápice em ponta, e a ventral digitiforme, com a extremidade bifurcada e cerdas apicais. Porção anterior do apódema ejaculador esférica.

Descrição. Macho, comprimento do corpo, 0,95 mm. Cabeça subcircular. Palpo maxilar com três segmentos (fig. 23); comprimento relativo dos segmentos do palpo: 1,0:0,6:0,7 (fig. 23); fossa sensorial localizada no primeiro segmento. Antena incompleta no espécime

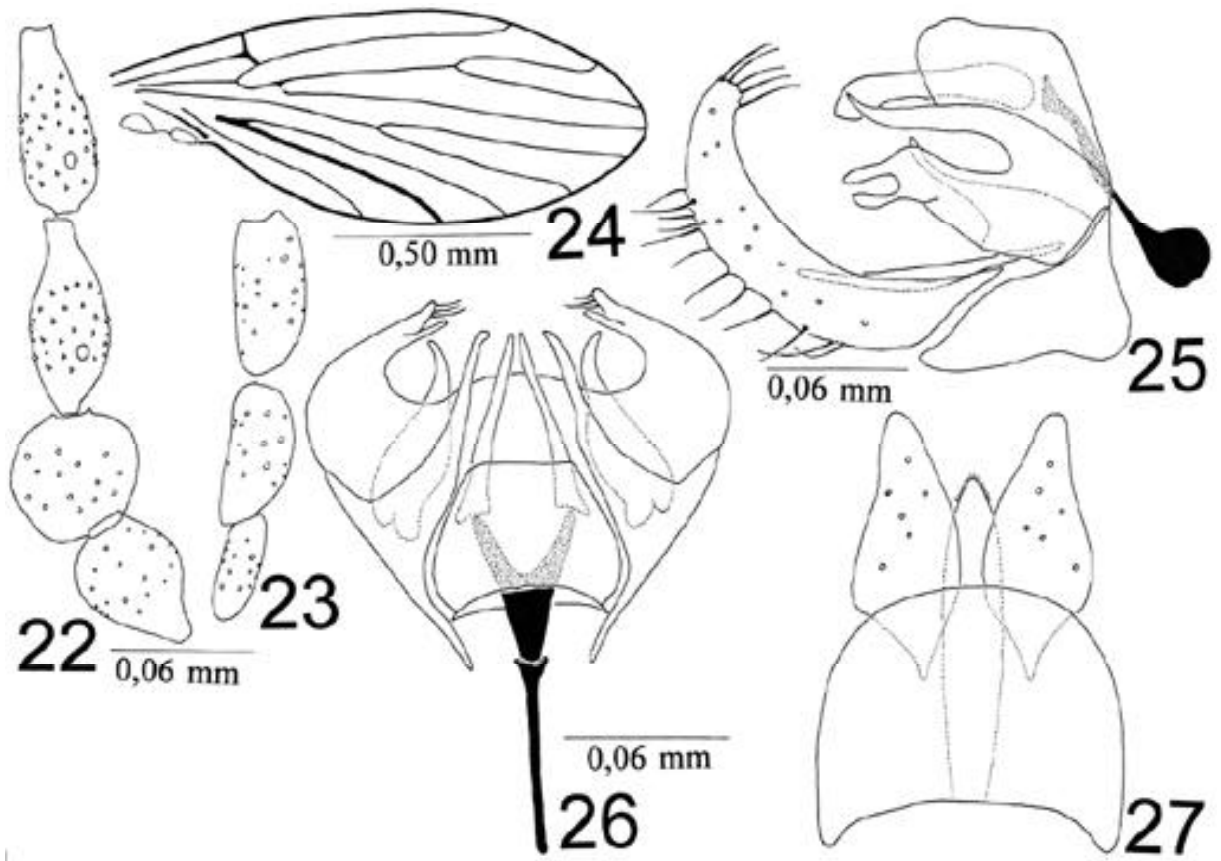

Figs. 22-27. Trichomyia silvatica sp. nov.: 22, escapo, pedicelo e primeiros flagelômeros; 23, palpo maxilar; 24, asa direita; terminália masculina: 25, lateral; 26, dorsal; 27 , ventral. 
estudado; escapo e pedicelo subesféricos, mais ou menos do mesmo tamanho (fig. 22); flagelômeros basais piriformes (fig. 22); ascóides perdidos no exemplar estudado. Comprimento da asa, $1,30 \mathrm{~mm}$; largura máxima, $0,46 \mathrm{~mm}$; r-m incompleta; $\mathrm{M}_{4}$ esclerotinizada; $\mathrm{m}$-cu ausente (fig. 24). Cercos e gonocoxitos com pilosidade (figs. 25, 27). Ápice do esternito $10 \mathrm{com}$ micropilosidade na superfície dorsal (fig. 27). Tergito 9 subquadrado, com a margem anterior arredondada (fig. 27). Cercos compridos, digitiformes, lateralmente em formato de $\mathrm{C}$ e com um grupo de cerdas grossas no ápice (fig. 25). Esternito 9 fundido aos gonocoxitos (fig. 26). Gonocoxitos com dois pares de projeções laterais (figs. 25, 26): a dorsal mais estreita que a projeção ventral, terminando em ponta (fig. 25, 26); a ventral longa, digitiforme, com o ápice bifurcado (figs. 25, 26) e cerdas longas no ápice (fig. 26). Gonóstilos articulados ventralmente aos gonocoxitos, pouco esclerotinizados (fig. 25). Tergito 10 não observado. Edeago simétrico, com um par de parâmeros digitiformes e estreitos (fig. 26); apódema ejaculador longo (figs. 31,32), com ápice semelhante a uma esfera (fig. 25). Apódema gonocoxal não observado.

\section{Trichomyia sulbaianensis sp. nov.}

(Figs. 28-33)

Material-tipo. BRASIL, Bahia: Itabuna (Reserva Ecológica CEPEC), holótipo on, parátipo $\sigma^{-2}$, 10.X.1985, P. S. Terra col. (CUFS). da Bahia.

Etimologia. O adjetivo específico sulbaianensis deriva do nome da macroregião sul

Diagnose. Palpo maxilar com três segmentos. Asa com r-m ausente. Terminália masculina: gonóstilos largos basalmente, mais estreitos apicalmente, com uma série de cerdas longas e grossas na margem superior apical. Cercos digitiformes, mais largos no ápice que na base, com cerdas longas e grossas. Apódema ejaculador cilíndrico.

Descrição. Macho, comprimento do corpo, 1,33 mm. Cabeça subcircular. Palpo maxilar com três segmentos; comprimento relativo dos segmentos do palpo: 1,0:0,6:0,4 (fig. 29); fossa sensorial no primeiro segmento. Antena incompleta no espécime estudado; escapo subcilíndrico e pedicelo subesférico, mais ou menos do mesmo tamanho (fig. 28); flagelômero basal piriforme (fig. 28); ascóides perdidos no espécime estudado. Comprimento da asa, $1,45 \mathrm{~mm}$; largura máxima, $0,55 \mathrm{~mm} ; \mathrm{M}_{4}$ bem esclerotinizada; $\mathrm{m}$-cu e r-m ausentes (fig. 30). Tergito 9, cercos e gonocoxitos com pilosidade (figs. 31, 33). Ápice do esternito $10 \mathrm{com}$ micropilosidade na superfície dorsal (fig. 33). Tergito 9 subquadrado (fig. 33). Tergito 10 não visível. Cercos compridos, digitiformes, com muitas cerdas longas e grossas (fig. 31). Esternito 9 fundido aos gonocoxitos, sem projeções (fig. 32). Gonóstilos longos, largos basalmente e estreitos apicalmente, com cerdas longas e grossas na margem superior apical (figs. 31, 32). Esternito 10 comprido, com micropilosidade dorsal (fig. 33). Edeago simétrico com um par de parâmeros (fig. 20). Ponte gonocoxal não observada. Apódema ejaculador longo (figs. 31, 32).

\section{Trichomyia teimosensis sp. nov.}

(Figs. 34-40)

Material-tipo. BRASIL, Bahia: Serra do Teimoso, holótipo ơ, 27.IV.2001, F. Bravo col. (CUFS); parátipos: Itabuna (Reserva Ecológica CEPEC), đ', 10.X.1987, P. S. Terra col. (CUFS); đ゙, II.1968, sem nome do coletor (CUFS); O', IX.1969. sem nome do coletor (CUFS). 


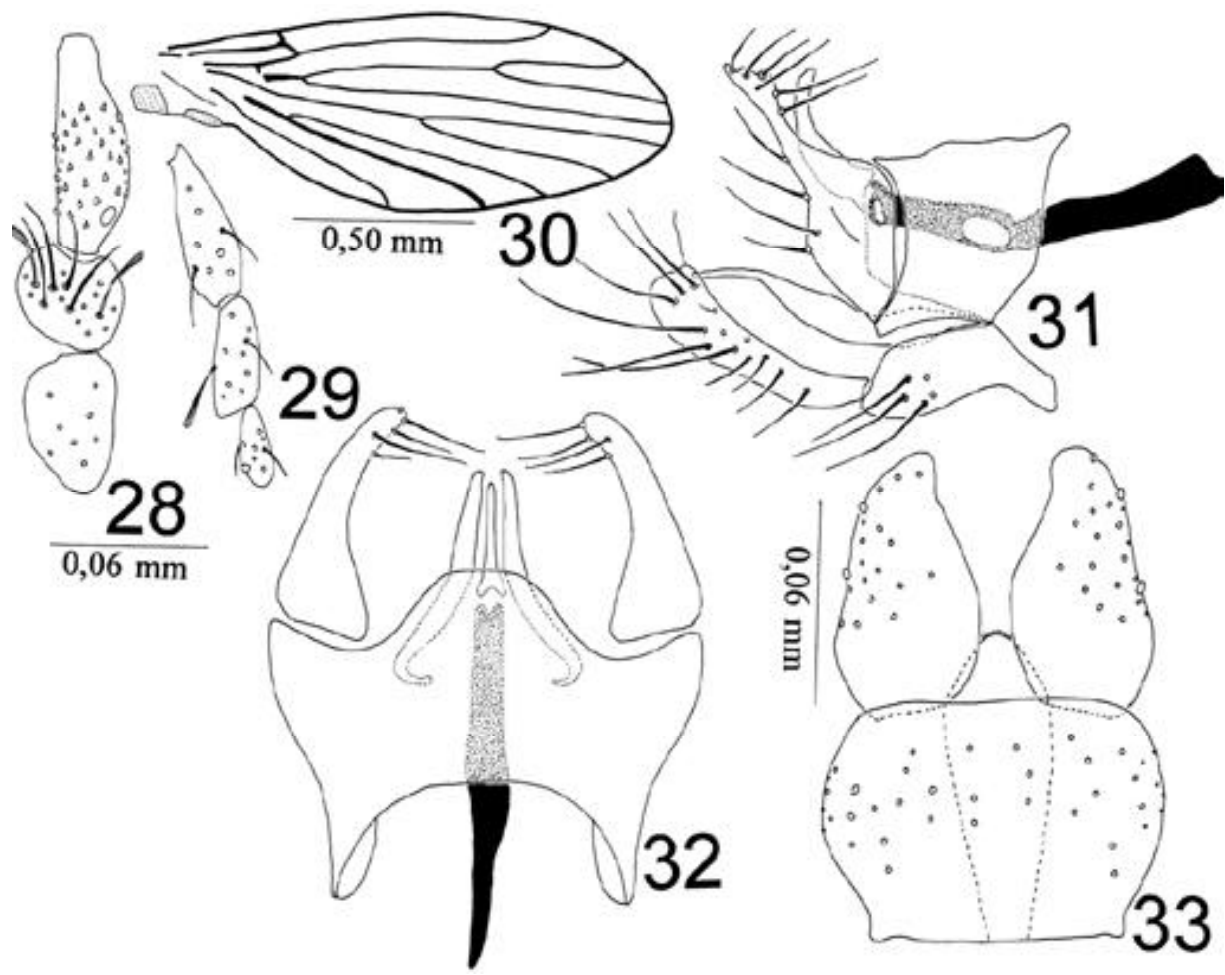

Figs. 28-33. Trichomyia sulbaianensis sp. nov.: 28, escapo, pedicelo e primeiro flagelômero; 29, palpo maxilar; 30, asa direita; terminália masculina: 31, lateral; 32, dorsal; 33, ventral.

Etimologia. O adjetivo específico deriva do nome Serra do Teimoso.

Diagnose. Palpo maxilar com três segmentos. Terminália masculina: gonocoxitos com dois pares de projeções laterais, a ventral menor que a dorsal, lateralmente de formato irregular e com cerdas grossas e longas no ápice; a dorsal, digitiforme, com cerdas longas e grossas na margem apical. Apódema ejaculador subcilíndrico.

Descrição. Macho, comprimento do corpo, 1,16 mm. Cabeça subcircular. Palpo maxilar com três segmentos; comprimento relativo dos segmentos do palpo: 1,0:0,6:0,7 (fig. 35); fossa sensorial no primeiro segmento (fig. 35). Antena incompleta no espécime estudado; escapo menor que o pedicelo, subesféricos (fig. 34); flagelômeros basais piriformes (fig. 34); ascóides perdidos no exemplar estudado. Comprimento da asa, 1,26 mm; largura máxima, $0,52 \mathrm{~mm}$; $\mathrm{r}-\mathrm{m}$ ausente; $\mathrm{M}_{4}$ bem esclerotinizada; $\mathrm{m}$-cu ausente (fig. 36). Tergito 9 , cercos e gonocoxitos com pilosidade (figs. 37,38). Ápice do esternito 10 com micropilosidade na superfície dorsal (fig. 38). Tergito 9 subquadrado (fig. 38). Cercos largos na base e estreitos no terço apical, com um par de cerdas apicais, curtas e grossas (fig. 37). Esternito 9 fundido aos gonocoxitos (fig. 40). Gonocoxitos com dois pares de projeções laterais (figs. 37, 39). Projeção dorsal digitiforme (fig. 37), com cerdas grossas na margem distal (figs. 37,40 ); projeção ventral irregular, com cerdas grossas na margem apical interna 


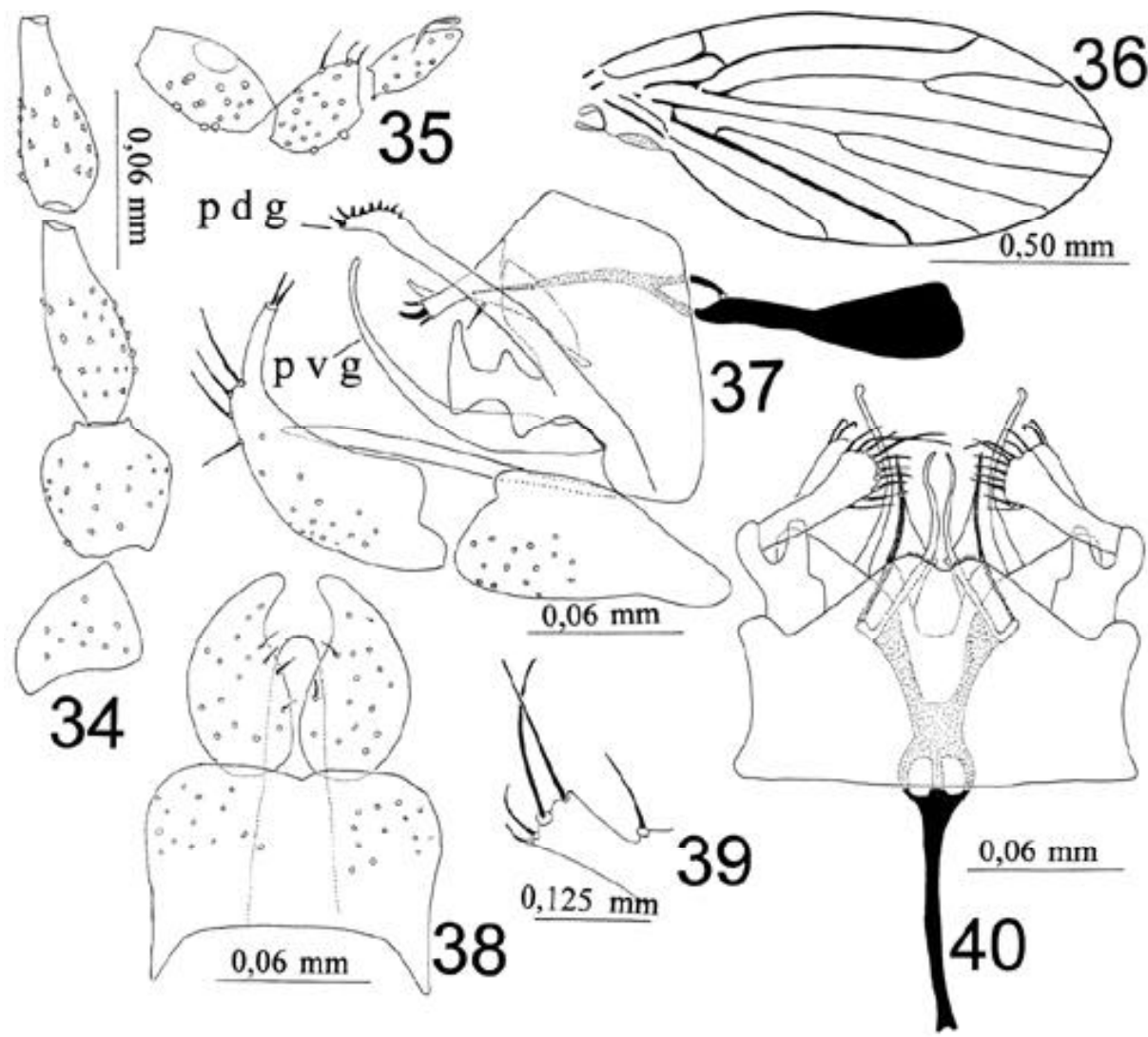

Figs. 34-40. Trichomyia teimosensis sp. nov.: 34, escapo, pedicelo e primeiros flagelômeros; 35, palpo maxilar; 36, asa direita; terminália masculina: 37, lateral; 38, ventral; 40, dorsal; 39, projeção ventral do gonocoxito, detalhe (projeção do gonocoxito: pdg, dorsal; pvg, ventral).

(figs. 39, 40), menor que a dorsal (fig. 37). Gonóstilos articulados ventralmente com os gonocoxitos, compridos, estreitos, com os ápices levemente curvados, pouco esclerotinizados (figs. 37, 40). Tergito 10 não observado. Edeago simétrico com par de parâmeros de estrutura complexa; na superfície dorsal, os parâmeros apresentam dois braços estreitos que terminam em ponta e na ventral são mais triangulares (fig. 40); apódema ejaculador longo, subcilíndrico (figs. 37, 40). Apódema gonocoxal não observado.

\section{DISCUSSÃO}

As espécies T. onorei e T. queirozi possuem quatro segmentos no palpo maxilar, com os dois primeiros parcialmente fundidos, característica observada apenas em algumas espécies neotropicais de Trichomyia (BRAvo, 2000). Trichomyia itabunesis, T. silvatica, T. sulbaianensis e Trichomyia teimosensis têm três segmentos no palpo maxilar, característica da maioria das espécies de Trichomyia do mundo inteiro (BRAVO, 2000). 
As espécies T. onorei e T. queirozi são muito semelhantes a T. biloba Quate, 1999 do Panamá (Quate, 1999). T. queirozi diferencia-se das outras duas pelo apódema ejaculador, curto e curvado ventralmente, situado em uma posição interna ao tergito $9 \mathrm{e}$ ao esclerito formado pela fusão do esternito 9 e gonocoxitos (gonocoxoesternito), enquanto que $T$. onorei e $T$. biloba apresentam um apódema ejaculador longo e não curvado ventralmente, projetado para fora do tergito 9 e do gonocoxoesternito.

As espécies T. onorei e $T$. biloba são muito similares, exceto pela margem posterior do gonocoxoesternito que na primeira espécie é reta e em $T$. biloba tem uma evaginação medial (QuATE, 1999).

Os gonóstilos de T. onorei e T. queirozi são muito semelhantes, sendo mais esclerotinizados e separados basalmente em T. queirozi. Em T. onorei, os gonóstilos, menos esclerotinizados, são fundidos basalmente. QuATE (1999), ao descrever T. biloba, denominou de edeago a um par de estruturas muito semelhantes às descritas como gonóstilos para $T$. onorei, ou seja, estruturas digitiformes, pouco esclerotinizadas e fundidas basalmente. O edeago é observado como estrutura independente em T. onorei e T. queirozi, sugerindo que a estrutura denominada de edeago por QUATE (1999) para T. biloba são os gonóstilos.

Na maioria das espécies de Trichomyia com três segmentos no palpo maxilar, o gonóstilo está articulado ventralmente ao gonocoxito. Tal característica foi observada em três das quatro espécies aqui descritas e nas espécies brasileiras conhecidas com esse número de segmentos no palpo maxilar. Em T. sulbaianensis, o gonóstilo está articulado dorsalmente ao gonocoxito.

Em Trichomyia itabunesis observou-se única projeção nos gonocoxitos, característica semelhante à observada em T. serrajiboiensis, T. ivani, e T. ramalhoi, descritas da Bahia por BRAvo (2001c). Nas espécies T. silvatica e T. teimosensis são observados dois pares de projeções laterais do gonocoxito, uma dorsal e outra ventral, semelhantes às observadas em T. bou Bravo, 1999, T. cauga Bravo, 1999, T. annae Bravo, 2001, T. danieli Bravo, 2001, T. iarae Bravo, 2001 e T. pedrabranquensis Bravo, 2001, descritas da Bahia (BRAVo, 1999; 2001c) e T. mishi, do Rio de Janeiro (Bravo, 1999).

\section{REFERÊNCIAS BIBLIOGRÁFICAS}

Alexander, B.; Freitas, J. M. \& Quate, L. W. 2001. Some Psychodidae (Diptera) from atlantic forest in south-eastern Brazil, with descriptions of Trichomyia dolichopogon sp. nov. and Trichomyia riodocensis sp. nov. Brazil. J. Biol., São Carlos, 61:467-474.

Barretto, M. P. 1954a. Novas espécies de Trichomyia Hal. do Brasil (Diptera, Psychodidae). Folia clin. biol., São Paulo, 21:127-137.

1954b. Sobre o gênero Eubonetia Vargas e Diaz-Nájera com a descrição de novas espécies do Brasil (Diptera, Psychodidae). Revta bras. Ent., São Paulo, 2:81-195.

Bravo, F. 1999. Septemtrichomyia, subgênero novo de Trichomyiinae neotropical (Diptera, Psychodidae). Revta bras. Ent., São Paulo, 43(1/2):1-7.

_. 2000. Descrição de uma espécie nova de Trichomyia (Diptera, Psychodidae) do sudeste brasileiro, com comentários sobre a genealogia do gênero. Acta biol. Leopoldensia, São Leopoldo, 22:185192.

2001a. Trichomyia quatei (Diptera, Psychodidae), uma nova espécie do nordeste brasileiro. Acta

biol. Leopoldensia, São Leopoldo, 23:31-37.

2001b. Opisthotrichomyia, subgênero novo de Trichomyiinae (Diptera, Psychodidae) e descrição de três novas espécies do Brasil. Stientibus, Sér. Ciênc. Biol., Feira de Santana, 1:50-55.

_. 2001c. Sete novas espécies de Trichomyia (Diptera, Psychodidae) da mata atlântica do nordeste do 
Brasil. Stientibus, Sér. Ciênc. Biol., Feira de Santana, 1:126-136.

Colless, D. H. \& McAlpine, D. K. 1991. Diptera. In: Csiro. The insects of Australia. Victoria, Melbourne University. p.717-786.

Coquillett, D. W. 1902. New orthorrhaphous Diptera from Mexico and Texas. Jl N. Y. ent. Soc., New York, 10:136-141.

Duckhouse, D. A. 1972. Psychodidae (Diptera, Nematocera) of southern Australia: subfamily Psychodinae. Trans. R. ent. Soc. Lond., London, 124:231-268.

1973. Psychodidae. In: Papavero, N. ed. A Catalogue of the Americas south of the United States. São Paulo, Universidade de São Paulo. v. 6, 29p.

McAlpine, J. F. 1981. Morphology and terminology: adults. In: McAlpine, J. F.; Peterson, B. V. et al. eds. Manual of Neartic Diptera, Ottawa, Research Branch, Agriculture Canada. v. 1, p.9-63. Monograph $\mathrm{n}^{\circ} 27$.

Quate, L. W. 1996. Preliminary taxonomy of Costa Rican Psychodidae (Diptera), exclusive Phlebotominae. Revta Biol. trop., San José, 1:1-81.

1999. Taxonomy of neotropical Psychodidae. (Diptera) 3. Psychodines of Barro Colorado island and San Blas, Panama. Mem. Ent. int., Gainesville, 14:409-441.

Rapp, W. F. 1945. New Psychodidae from Barro Colorado Island. Jl N. Y. ent. Soc., New York, 53:309-311.

Satchell, G. H. 1956. On the genus Trichomyia (Diptera: Psychodidae), with descriptions of four new species. Proc. R. ent. Soc. Lond., (B), London, 25:147-156.

W AGNER, R. 1993. On a collection of Psychodidae (Diptera) by Dr. L. Botosaneanu from some caribbean islands. Aquatic Insects, Lisse, 15:109-127.

- 1999. Psychodidae from the Dominican Republic: records and descriptions of new species (Insecta: Diptera). J. Kans. ent. Soc., Kansas, 72:233-245.

Wagner, R. \& Masteller, E. C. 1996. New moth flies (Diptera: Psychodidae) and a key to species from Puerto Rico. Proc. ent. Soc. Wash., Washington, 98:450-464.

Recebido em 11.12.2001; aceito em 13.06.2002. 